\title{
Marker expression reveals heterogeneity of spermatogonia in the neonatal mouse testis
}

\author{
Bryan A Niedenberger ${ }^{1}$, Jonathan T Busada ${ }^{1}$ and Christopher B Geyer ${ }^{1,2}$ \\ ${ }^{1}$ Department of Anatomy and Cell Biology, Brody School of Medicine and ${ }^{2}$ East Carolina Diabetes and \\ Obesity Institute, East Carolina University, Greenville, North Carolina 27834, USA
}

Correspondence should be addressed to C B Geyer; Email: geyerc@ecu.edu

\begin{abstract}
Prospermatogonia transition to type A spermatogonia, which provide the source for the spermatogonial stem cell (SSC) pool. A percentage of these type A spermatogonia then differentiate to enter meiosis as spermatocytes by $\sim$ P10. It is currently unclear as to when these distinct populations are initially formed in the neonatal testis, and when the expression of markers both characteristic of and required for the adult undifferentiated and differentiating states is established. In this study, we compared expression of known spermatogonial cell fate markers during normal development and in response to the differentiation signal provided by retinoic acid (RA). We found that some markers for the undifferentiated state (ZBTB16/PLZF and CDH1) were expressed in nearly all spermatogonia from P1 through P7. In contrast, differentiation markers (STRA8 and KIT) appeared in a subset of spermatogonia at P4, coincident with the onset of RA signaling. GFRA1, which was present in nearly all prospermatogonia at P1, was only retained in STRA8/KIT - spermatogonia. From P4 through P10, there was a great deal of heterogeneity in the male germ cell population in terms of expression of markers, as markers characteristic of the undifferentiated (except GFRA1) and differentiating states were co-expressed through this interval. After P10, these fate markers diverged to mark distinct populations of undifferentiated and differentiating spermatogonia, and this pattern was maintained in juvenile ( $\mathrm{P18}$ ) and adult ( $\mathrm{P}>60$ ) testes. Taken together, these results reveal that the spermatogonia population is heterogeneous during the first wave of spermatogenesis, and indicate that neonatal spermatogonia may not serve as an ideal substitute for studying the function of adult spermatogonia.
\end{abstract}

Reproduction (2015) 149 329-338

\section{Introduction}

In the mouse, prospermatogonia (also called gonocytes and, less commonly, prespermatogonia) proliferate briefly after sex determination in the fetal testis, and then enter a prolonged quiescent period from approximately embryonic (E) day 14.5 until postnatal $(P)$ days 1-2 (Vergouwen et al. 1991, Western et al. 2008). At that point, neonatal prospermatogonia begin to move to the periphery of the testis cords and resume mitosis as spermatogonia, marking the initiation of spermatogenesis (Nagano et al. 2000, Drumond et al. 2011). Spermatogonia become flanked by Sertoli cells within the cord and myoid cells outside the cord, and respond to juxtacrine and paracrine signals from these somatic cells in this 'niche' to either remain undifferentiated ( $\left.A_{\text {undiff }}\right)$ or differentiate $\left(A_{\text {diff }}\right)$ to ultimately enter meiosis by P10 (de Rooij 2001). This is termed the first wave of spermatogenesis, and it does not rely upon stem cell function, indicating that the first complement of sperm develop directly from this first group of spermatogonia (Yoshida et al. 2006). In subsequent waves, the spermatogonial stem cell (SSC) population provides a consistent source of progenitor spermatogonia that differentiate to ensure fertility for the remainder of the male reproductive lifespan.

$A_{\text {undiff }}$ and $A_{\text {diff }}$ spermatogonia are further characterized based on their topology; the most well-accepted current model predicts that stem cell potential predominates in individual $A_{s}$ spermatogonia, and this potential progressively diminishes as they divide into clones with retained intercellular bridges $\left(\mathrm{A}_{\mathrm{pr}}-\mathrm{A}_{\mathrm{al}}\right.$; Yang \& Oatley 2014). Although spermatogonial development begins shortly after birth in the mouse, it is unclear how similar development during the first wave of spermatogenesis is to that during steady-state spermatogenesis in the adult. This is an important point, as numerous studies utilize isolated spermatogonia from neonatal mice (especially at P7, where there are a relatively high percentage of the testicular cell population) as a substitute for adult spermatogonia. Recent studies have suggested that functional differences exist between neonatal and adult spermatogonia. Replication-dependent viruses more readily transduced spermatogonia from neonatal mice compared with their adult counterparts, suggesting that these spermatogonia divide more 
rapidly (Nagano et al. 2001, 2002). In support of this concept, de Rooij et al. demonstrated that spermatogonial development is accelerated in juvenile rats and hamsters (van Haaster \& de Rooij 1993). A comparison of germ cell transplantation results from neonatal (P6) and adult mice revealed that the recolonization index for pup SSCs was half that of the adult, indicating delayed proliferation/expansion after transplantation and suggesting a difference in the ability of these spermatogonia to self-renew and differentiate (Ebata et al. 2007).

It is unclear whether prospermatogonia transition to SSCs, which then differentiate, or whether both populations arise directly from prospermatogonia. In addition, little is currently known regarding the cell fate decisions that take place in the neonatal testis, which result in creation of a functional stem cell population. In the adult testis, type A spermatogonia are classified functionally as stem cell and progenitor (both undifferentiated and differentiating). These adult populations are distinguishable at the histological level by their morphology and the stage of the seminiferous epithelium in which they reside. In addition, a number of protein markers have been identified that are differentially expressed in spermatogonia that are undifferentiated (e.g., ZBTB16/PLZF, ID4, GFRA1, RET, and Neurog3/Ngn3) and differentiating (e.g., STRA8, KIT, SOHLH1, and SOHLH2) (reviewed by Yang \& Oatley (2014)). Immunostaining results from several studies using adult tissues revealed that there is heterogeneity among the spermatogonial population (Nakagawa et al. 2007, Grisanti et al. 2009, Suzuki et al. 2009). However, it is currently unclear whether this has phenotypic consequence or whether heterogeneity is observed as the spermatogonial population is created in the neonatal testis.

We undertook this study to answer several important questions that have not been addressed in the neonatal testis. First, using established adult spermatogonial cell fate markers, are there homogenous or heterogeneous populations during the first wave of spermatogenesis? Secondly, when do markers of cell fate diverge during the first wave of spermatogenesis? Thirdly, how do neonatal spermatogonia respond to a differentiation signal (retinoic acid (RA)) by modifying expression of cell fate markers? In this study, we report that spermatogonia constitutively express certain markers of undifferentiated fate (CDH1 and ZBTB16) through $\sim$ P10, but express the receptors GFRA1 or KIT (or neither) during this interval. This suggests that there are three subpopulations of spermatogonia in the neonatal testis: GFRA1 +/KIT - (undifferentiated, can respond to GDNF), GFRA1 - /KIT + (differentiating, can respond to KITL), or GFRA 1 - /KIT - (potentially uncommitted to a specific cell fate). This third subpopulation progressively decreases as the KIT + population increases, suggesting that these spermatogonia are differentiating at later points to generate the asynchrony observed in the adult testis.

\section{Materials and methods}

\section{Animal care}

CD-1 mice were used for all analyses except where indicated otherwise. In particular, the Id4-GFP mice were backcrossed onto a C57Bl/6 background (Chan et al. 2014). Animal procedures were performed in accordance with the National Research Council Guide for the Care and Use of Laboratory Animals and approved by the Animal Care and Use Committee of East Carolina University (AUP \#A178a). RA injections were administered as reported previously, and mice were killed by decapitation (P0-P10) or by $\mathrm{CO}_{2}$ asphyxiation followed by thoracotomy (P18 and P>60) (Busada et al. 2014).

\section{Tissue processing for histological analysis}

Testes for histological analysis were fixed for $1 \mathrm{~h}$ to overnight in Bouin's solution (Ricca Chemical, Arlington, TX, USA) at $4{ }^{\circ} \mathrm{C}$, washed in multiple changes of $1 \times \mathrm{PBS}$, dehydrated through an ethanol series, and processed for paraffin embedding. Sections of $5 \mu \mathrm{m}$ thickness were cut and stained with hematoxylin and eosin (H\&E) using standard methods. Images were taken using an Axio Observer A1 microscope (Carl Zeiss Microscopy, LLC) equipped with a XL16 digital camera and Exponent version 1.3 Software (Dage-MTI, Michigan City, IN, USA).

\section{Immunostaining frozen sections}

Testes were fixed for $2 \mathrm{~h}$ to overnight in $4 \%$ paraformaldehyde (PFA), washed multiple times in $1 \times$ PBS, transferred to $30 \%$ sucrose, embedded in O.C.T, and stored at $-80{ }^{\circ} \mathrm{C}$. Sections of $5 \mu \mathrm{m}$ thickness were cut and placed on positively charged slides and stored at $-20{ }^{\circ} \mathrm{C}$ before use. Immunolabeling was performed by standard methods. Briefly, blocking and antibody incubations were carried out at room temperature in $1 \times$ PBS containing $3 \%$ $\mathrm{BSA}+0.1 \%$ Triton $\mathrm{X}-100$, and stringency washes were performed with $1 \times$ PBS $+0.1 \%$ Triton $X-100$. Sections were blocked for $1 \mathrm{~h}$ before incubation with a primary antibody for $1 \mathrm{~h}$ (see Table 1). Secondary antibodies (1:500, Alexa Fluor-488 or -555, Invitrogen) plus phalloidin-635 (1:500, Life Technologies) were incubated for $1 \mathrm{~h}$ at room temperature. Primary antibody was omitted as a negative control. Cover slips were mounted with Vectastain containing DAPI (Vector Laboratories, Burlingame, CA, USA), and images obtained using a Fluoview FV1000 confocal laser-scanning microscope (Olympus America). Immunolabeling was performed in triplicate on testes from at least two different animals. Images used for quantitation were assessed using ImageJ (U. S. National Institutes of Health, Bethesda, MD, USA). Between 21 and 30 cords from at least two different animals were counted. Each marker was co-stained with DDX4 to label all germ cells. Cells were counted as positive for a marker when selected by the threshold tool using the default algorithm. Thresholds for each marker counted were as follows: STRA8 $=$ 70-255, KIT $=70-255$, DDX4 =100-255, ZBTB16=50-255, $\mathrm{CDH} 1=100-255$, and GFRA $1=50-255$. 
Table 1 Primary antibodies.

\begin{tabular}{|c|c|c|c|}
\hline Protein & $\begin{array}{l}\text { Spermatogonia } \\
\text { expression }\end{array}$ & References & Antibody \\
\hline STRA8 & $A_{\text {diff }}\left(A_{1}-\right)$ & Zhou et al. (2008a) & Abcam rabbit polyclonal (49602), 1:3000 \\
\hline KIT & $A_{\text {diff }}\left(A_{1}-\right)$ & $\begin{array}{l}\text { Mithraprabhu \& } \\
\text { Loveland (2009) }\end{array}$ & $\begin{array}{l}\text { Santa Cruz goat polyclonal (sc-1494), 1:1000 } \\
\text { Cell Signaling rabbit polyclonal (3074S), 1:1000 }\end{array}$ \\
\hline ZBTB16/PLZF & $A_{\text {undiff }}\left(A_{s}, A_{p r}, A_{a l}\right)$ & $\begin{array}{l}\text { Buaas et al. (2004) and } \\
\text { Costoya et al. (2004) }\end{array}$ & Santa Cruz rabbit polyclonal (sc-22839), 1:500 \\
\hline DDX4/VASA/MVH & $\mathrm{A}_{\text {undiff }}$ and $\mathrm{A}_{\text {diff }}$ & & $\begin{array}{l}\text { Abcam rabbit polyclonal (ab-13840), 1:250 } \\
\text { R\&D Systems goat polyclonal (AF2030), 1:800 }\end{array}$ \\
\hline CDH1/ECAD & $A_{\text {undiff }}\left(A_{s}, A_{p r}, A_{a l}\right)$ & Tokuda et al. (2007) & Cell Signaling rabbit polyclonal (3195P), 1:200 \\
\hline GFRA1 & $A_{\text {undiff }}\left(A_{s}, A_{p r}\right)$ & $\begin{array}{l}\text { Naughton et al. (2006) and } \\
\text { Grasso et al. (2012) }\end{array}$ & R\&D Systems goat polyclonal (AF560), 1:200 \\
\hline
\end{tabular}

\section{Whole-mount immunostaining of testis cords}

Testes were first decapsulated, and then cords were mechanically separated. Cords were fixed for $1 \mathrm{~h}$ in $4 \%$ paraformaldehyde and washed multiple times in $1 \times$ PBS. Individual cords were transferred to slides and IIF performed by standard methods. Briefly, blocking and antibody incubations were carried out at room temperature in $1 \times$ PBS containing $3 \%$ BSA $+0.1 \%$ Triton $X-100$, and stringency washes were performed with $1 \times$ PBS $+0.1 \%$ Triton X-100. Secondary antibodies (1:500, Alexa Fluor-488 or -555, Life Technologies) were incubated for $1 \mathrm{~h}$ at room temperature. Primary antibody was omitted as a negative control, and fluorescent images were obtained as described earlier in this study.

\section{Results}

\section{Heterogeneity in neonatal germ cell morphology}

Male germ cell development in neonatal mice ( P0-P7) has been described largely based on changes in cellular morphology. Some studies have suggested that homogenous populations exist during this time (e.g., Bellve et al. 1977), while others reported type A spermatogonia with a distinct morphology (e.g., Kluin \& de Rooij 1981). We carefully examined the morphology and nuclear diameter of germ cells in CD-1 mice, which we have used for our recent studies. Germ cells are readily identified based on established morphological characteristics (Kluin \& de Rooij 1981), and identification can be verified by immunostaining for ZBTB16/PLZF (Supplementary Figure S1A, B, and C, see section on supplementary data given at the end of this article), which was detectable in all germ cells in the neonatal testis, as we have reported previously (Busada et al. 2014). The prospermatogonia population at $P 1$ appeared homogenous, with germ cells sharing similar nuclear diameters and chromatin morphologies. In contrast, at P4, the spermatogonia population appeared heterogeneous, with differing nuclear diameters and chromatin morphology (Fig. 1), which supports the potential for multiple spermatogonial types as early as P4.

\section{Cell fate marker expression in neonatal prospermatogonia (P1)}

There have been no published comprehensive analyses of neonatal spermatogonia development using established adult fate markers. Therefore, it is not clear when specific spermatogonial cell types appear in the neonatal testis, as it is difficult to distinguish undifferentiated and differentiating type A spermatogonia based solely on morphological criteria. Shortly after birth (P1), the testis cords contain peripherally located dividing Sertoli cells and centrally located quiescent prospermatogonia (de Rooij \& Griswold 2012). To determine as to what percentage of prospermatogonia express certain spermatogonial fate markers, we co-immunolabeled with antibodies against CDH1, ZBTB16, and GFRA1 (undifferentiation markers) and KIT and STRA8 (differentiation markers) along with an antibody against the pan germ cell marker DDX4, which enabled us to determine the percentage of germ cells expressing various cell fate markers. Approximately $100 \%$ of $\mathrm{P} 1$ prospermatogonia had detectable levels of CDH1, ZBTB16, and GFRA1, but almost none had detectable expression of the differentiation markers KIT or STRA8 (Fig. 2 and Supplementary Figure S2, see section on supplementary data given at the end of this article).

\section{Cell fate marker expression in P4-P10 spermatogonia}

We then examined marker expression at $\mathrm{P} 4$, a time when the testis contains morphologically distinct populations of spermatogonia (Kluin \& de Rooij 1981; Fig. 1). We hypothesized that the presence of morphological differences indicates various degrees of spermatogonial differentiation. To examine this, we co-localized ZBTB16, CDH1, and STRA8 with GFRA1 and KIT, canonical markers of undifferentiated and differentiating spermatogonia respectively (Oulad-Abdelghani et al. 1996, Buaas et al. 2004, Costoya et al. 2004, Buageaw et al. 2005, Prabhu et al. 2006, Tokuda et al. 2007, Zhou et al. 2008a, Grisanti et al. 2009, Mithraprabhu \& Loveland 2009, Grasso et al. 2012). At P4, there were largely distinct subpopulations of spermatogonia that 

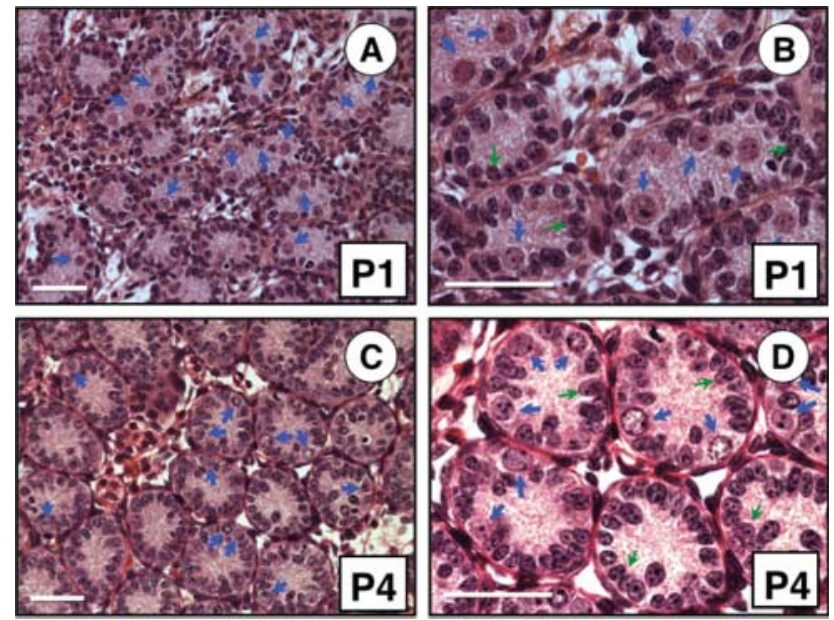

Figure 1 Spermatogonia exhibit morphological heterogeneity by $\mathrm{P} 4$. Sections from Bouin's solution-fixed testes from mice at P1 (A and B) and P4 (C and D) were stained with H\&E. Blue arrows identify prospermatogonia (A and B) and spermatogonia, the latter of which exhibited a number of different nuclear sizes and morphologies (C and D). Green arrows (B and D) indicate representative Sertoli cells. Scale bars $=60 \mu \mathrm{m}$.

were either GFRA $1+(60 \%)$ or KIT $+(35 \%)$, and $<10 \%$ of the population were GFRA $1+/ \mathrm{KIT}+$ (Fig. 3 and Supplementary Figures S2, S3 and S4, see section on supplementary data given at the end of this article). All spermatogonia stained positive for both ZBTB16 and $\mathrm{CDH} 1$, accepted markers of the undifferentiated fate. In addition, nearly all KIT + spermatogonia were STRA8 + (Busada et al. 2015), indicating that these cells had been exposed to RA. Considering only these markers, it is clear that at least two unique populations of spermatogonia exist in the testis at P4 (GFRA1+/KIT $-/ \mathrm{CDH} 1+$ / ZBTB16+/STRA $8-$ and GFRA $1-/ \mathrm{KIT}+/ \mathrm{CDH} 1+/$ ZBTB16+/STRA8 +). In addition, based on germ cell identification by DAPI staining, it is apparent that small populations of spermatogonia are KIT-/GFRA1 - .

By P7, all differentiating $(\mathrm{KIT}+)$ spermatogonia remained $\mathrm{CDH} 1+$ and $80 \%$ were still ZBTB16+, and there was almost no overlap in GFRA1 and KIT expression (17 and $42 \%$ of DDX4 + cells respectively). We observed this same relationship in spermatogonia in $\mathrm{C} 57 \mathrm{BI} / 6$ testes at P6 (Supplementary Figure S3). However, a correlation between staining intensity became apparent in a subset of spermatogonia (e.g., strong KIT + with weak ZBTB16+). In addition, there was less observed STRA8 and KIT co-expression observed in P4 spermatogonia, which resulted in populations that were KIT+/STRA8+, KIT+/STRA8-, and KIT-/STRA8+ (Fig. 4). Analysis of these markers alone indicated that multiple distinct populations of germ cells exist at P7 (GFRA1+/KIT $-/ \mathrm{CDH} 1+/$ ZBTB16+/STRA8 - , GFRA1 -/KIT +/CDH1 +/ZBTB16 +/STRA $8+$, GFRA $1-/$ KIT + /CDH1 + /ZBTB16 + / STRA8 - , GFRA1 -/KIT -/CDH1 +/ZBTB16+/STRA8+, and GFRA1 -/KIT-/CDH1+/ZBTB16-/STRA8 + and GFRA1 -/KIT +/CDH1 +/ZBTB16-/STRA8-).

By P10, GFRA1 and KIT were still detectable in distinct populations (8 and $75 \%$ of DDX $4+$ cells respectively), but there was a stark divergence in the expression of undifferentiated markers ZBTB16 and CDH1. All spermatogonia that were GFRA1 + were $\mathrm{CDH} 1+$ / ZBTB16+, but most KIT + cells were now $\mathrm{CDH} 1-$ (Fig. 5). In addition, the staining intensity began to correlate with presumed cell fate; for example, KIT+

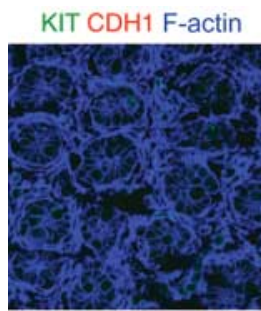

KIT ZBTB16 F-actin
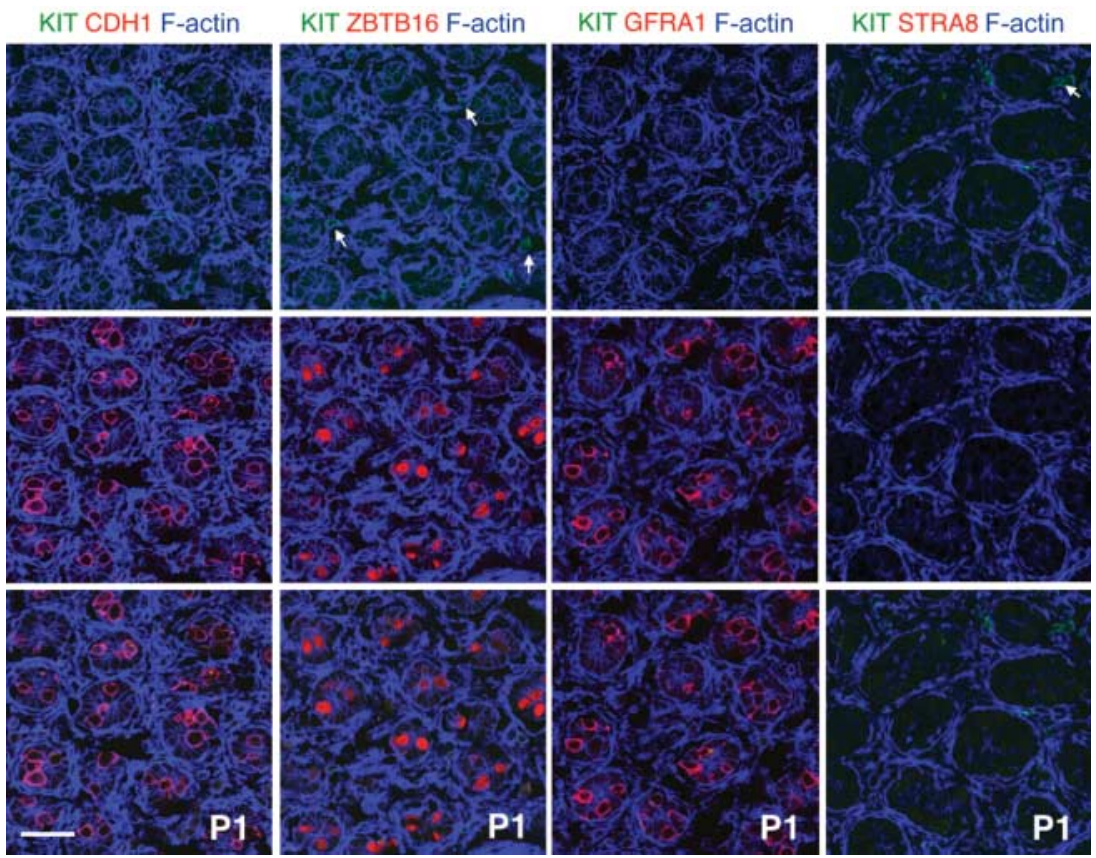

Figure 2 Fate marker detection in germ cells of the neonatal testis at P1. Phalloidin was used to label F-actin (blue) in all images. Each column contains one representative section labeled with antibodies against the proteins listed at the top. The first row is green + blue channels, the second is red+blue, and the bottom row is a merged image of green + red+blue. White arrows indicate KIT + interstitial cells, which are present throughout testis development (Rothschild et al. 2003). Scale bar $=60 \mu \mathrm{m}$. 

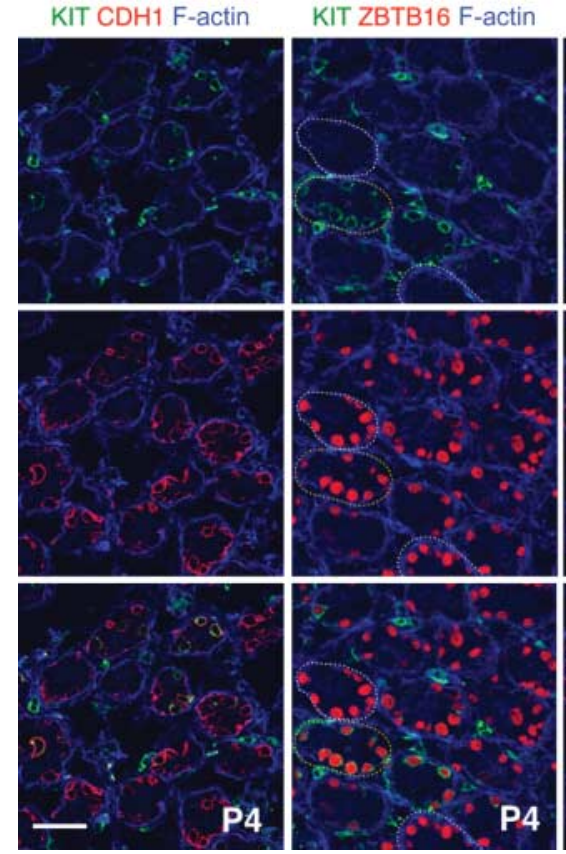

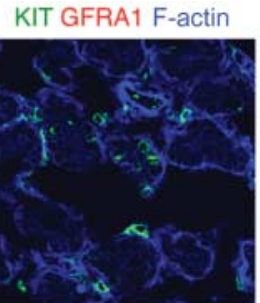

KIT STRA8 F-actin
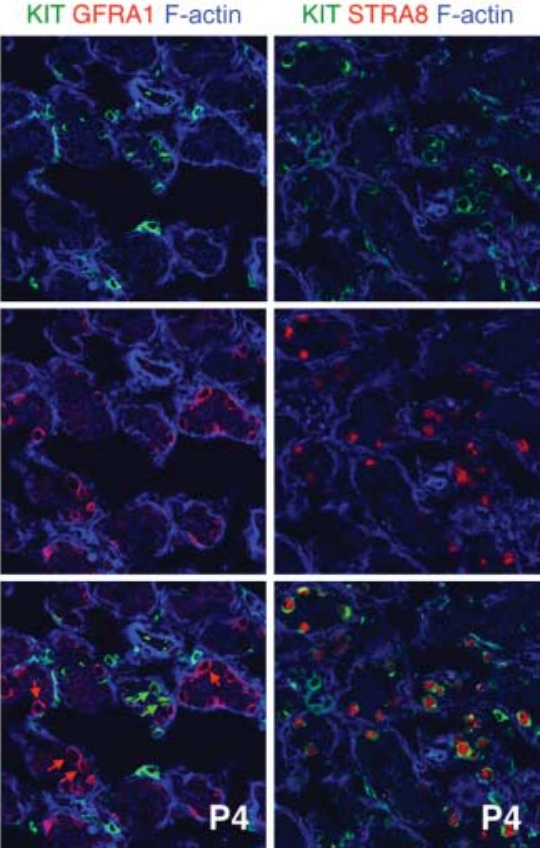

Figure 3 Fate marker detection in germ cells of the neonatal testis at P4. Phalloidin was used to label F-actin (blue) in all images. Each column contains one representative section labeled with antibodies against the proteins listed at the top. The first row is green+blue channels, the second is red+blue, and the bottom row is a merged image of green + red + blue. Cords containing ZBTB16+ spermatogonia were either KIT + (yellow dashed lines) or KIT - (white dashed lines). Green arrows indicate $\mathrm{KIT}+$ spermatogonia and red arrows point to GFRA $1+$ spermatogonia. Scale bar $=60 \mu \mathrm{m}$. cells had weak staining for ZBTB16, and the opposite was also true (strong ZBTB16 correlated with weak or no staining for KIT). As at P7, there were three distinct populations of differentiating cells that were $\mathrm{KIT}+/$ STRA8+, KIT+/STRA8-, and KIT-/STRA8+. The latter population was centrally located in the testis cords, and probably are preleptotene spermatocytes, which have the highest levels of STRA8 (Zhou et al. 2008a). We co-immunostained testis cords with ZBTB16 and GFRA1 or KIT to determine whether GFRA1 or KIT staining correlated with spermatogonial chain length.
As expected, GFRA1 was primarily detected in $A_{s}$ and $A_{\text {pr }}$ spermatogonia, while KIT was detected in longer chains (Supplementary Figure S4).

It has been recently demonstrated that ID4 was enriched in $\mathrm{A}_{\mathrm{s}} \mathrm{SSCs}$, and that transgenic mice faithfully expressed GFP downstream of an Id4 promoter in SSCs (Oatley et al. 2011, Chan et al. 2014). We obtained testes from Id4-GFP mice at P6 and co-localized GFP with GFRA1 and KIT, as these largely marked unique populations of spermatogonia. We found that, in general, GFRA1 signal was strongest in spermatogonia
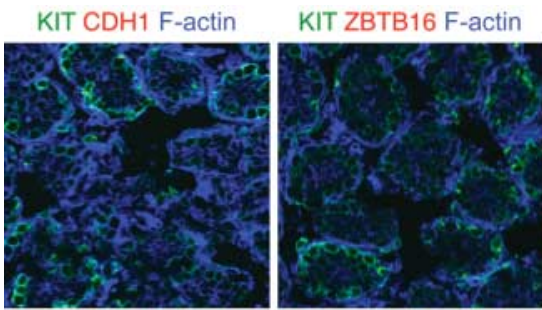

KIT GFRA1 F-actin
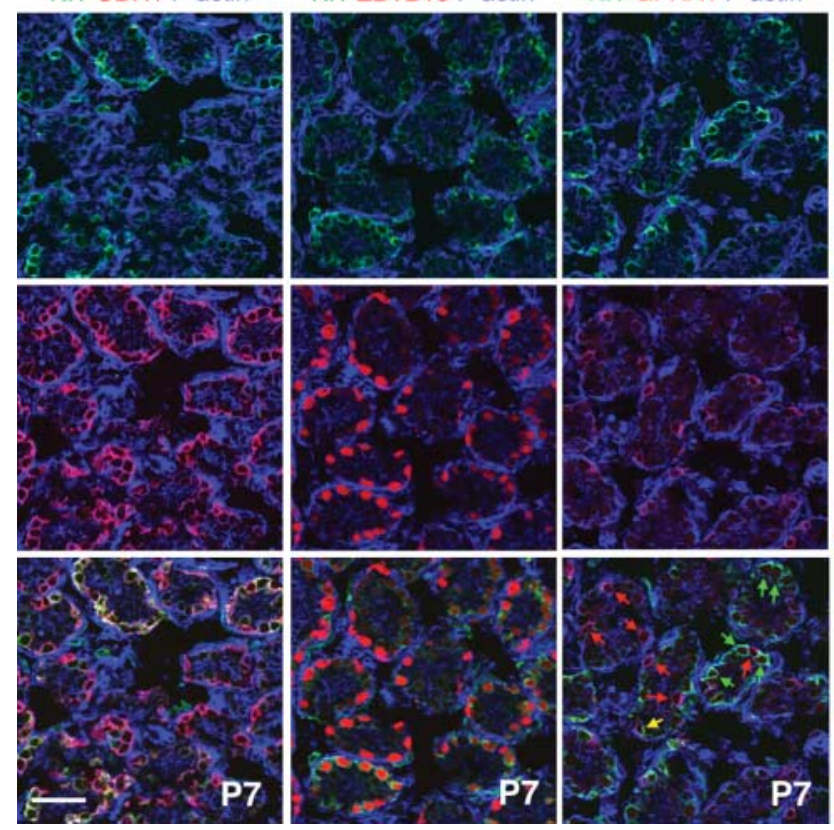

KIT STRA8 F-actin

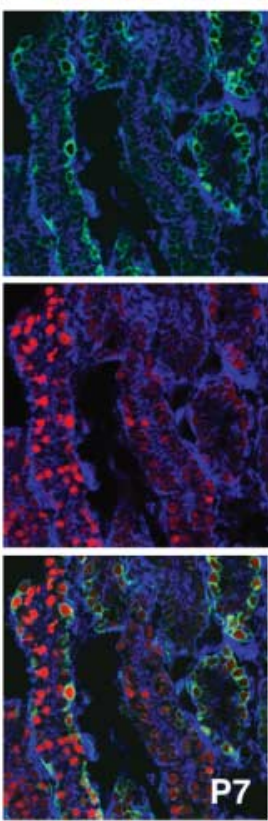

Figure 4 Fate marker detection in germ cells of the neonatal testis at P7. Phalloidin was used to label F-actin (blue) in all images. Each column contains one representative section labeled with antibodies against the proteins listed at the top. The first row is green+blue channels, the second is red+blue, and the bottom row is a merged image of green + red+blue. Red arrows indicate GRFA1 + /KIT spermatogonia, green arrows indicate GFRA1 - / KIT + spermatogonia, and the yellow arrow points to a rare GFRA $1+/ \mathrm{KIT}+$ spermatogonium. Scale bar $=60 \mu \mathrm{m}$. 


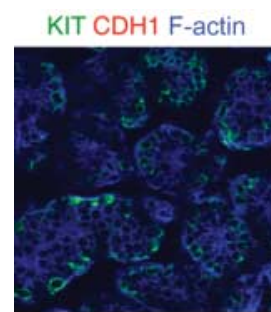

KIT ZBTB16 F-actin
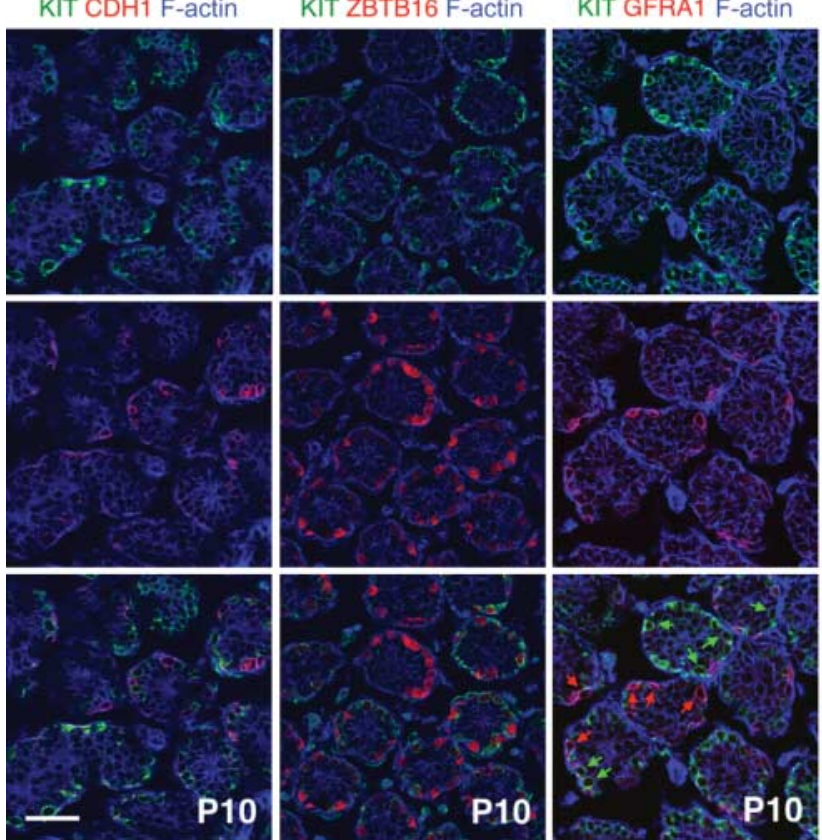

with bright GFP, and that KIT signal was strongest in spermatogonia with dim or absent GFP signal (Supplementary Figure S5, see section on supplementary data given at the end of this article).

\section{Cell fate marker expression in the P18 and adult $(P>60)$ testis}

By P1 8 in the mouse, the blood-testis barrier was formed, Sertoli cells no longer divide, lumina have appeared, and the seminiferous epithelia contain spermatogonia and spermatocytes at various stages of progression through
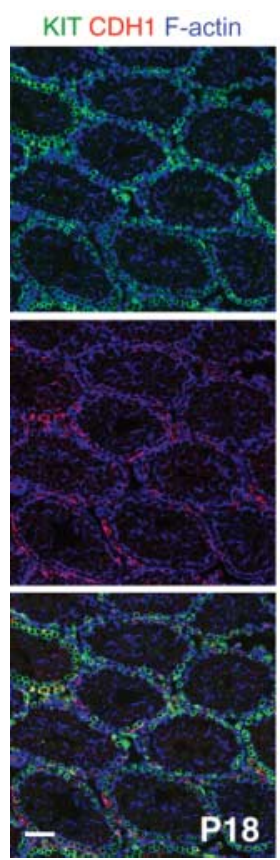
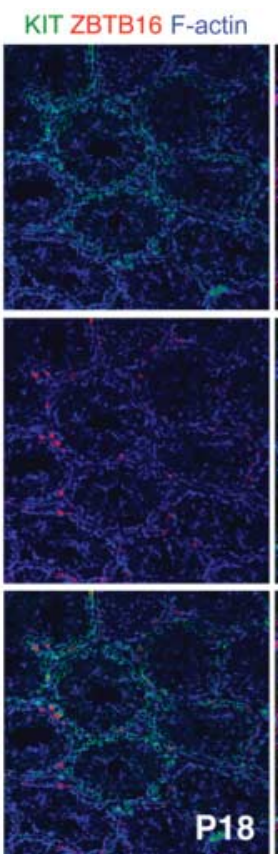

KIT GFRA1 F-actin
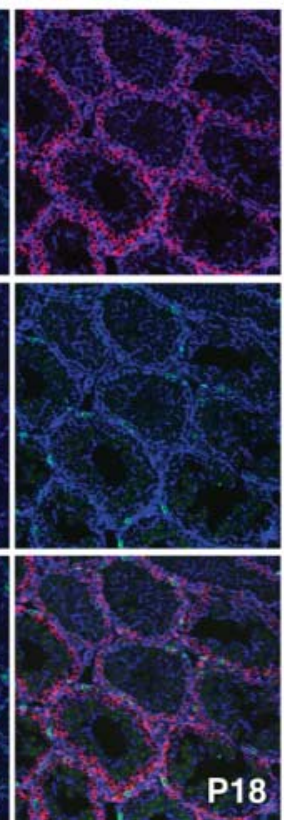

KIT STRA8 F-actin
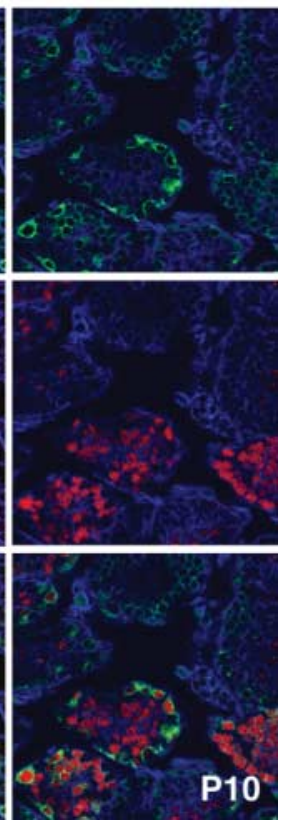

Figure 5 Fate marker detection in germ cells of the neonatal testis at P10. Phalloidin was used to label F-actin (blue) in all images. Each column contains one representative section labeled with antibodies against the proteins listed at the top. The first row is green + blue channels, the second is red + blue, and the bottom row is a merged image of green + red + blue. Red arrows indicate GRFA1 +/KIT - spermatogonia and green arrows indicate GFRA1 - /KIT + spermatogonia. Scale bar $=60 \mu \mathrm{m}$.

meiosis, but haploid round spermatids are not yet present (Griswold 1998, Hess \& Renato de Franca 2008). The examination of fate markers revealed that KIT staining was weak or absent in nearly all ZBTB16+, $\mathrm{CDH} 1+$, and GFRA1 + spermatogonia (Fig. 6). There were STRA8+/ $\mathrm{KIT}+$, STRA8+/KIT - , and STRA $8-/ \mathrm{KIT}+$ germ cells, but these populations were present in separate tubules (Fig. 6). Therefore, there was significant separation of the classic spermatogonial cell fate markers by this time, and this continued into adulthood (Supplementary Figure S6, see section on supplementary data given at the end of this article).

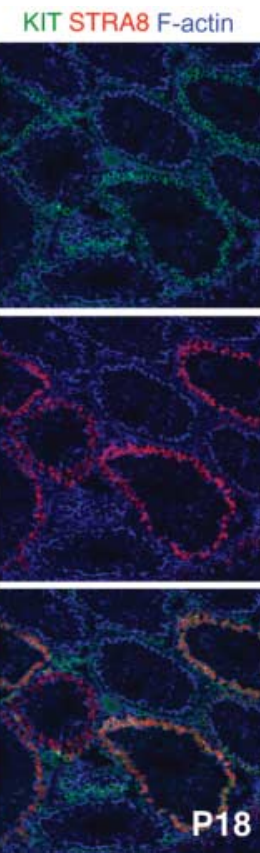

Figure 6 Fate marker detection in germ cells of the neonatal testis at P18. Phalloidin was used to label F-actin (blue) in all images. Each column contains one representative section labeled with antibodies against the proteins listed at the top. The first row is green + blue channels, the second is red+blue, and the bottom row is a merged image of green + red + blue. Scale bar $=60 \mu \mathrm{m}$. 


\section{How does marker expression change in response to a differentiation signal?}

Spermatogonia differentiate in response to RA, beginning in the neonatal testis at P3-P4 and then throughout the remainder of the male reproductive lifespan (van Pelt \& de Rooij 1991, Gaemers et al. 1998, Zhou et al. 2008a, Snyder et al. 2011, Busada et al. 2014). We utilized an in vivo model of spermatogonial differentiation, in which we administered exogenous RA at P1, 2-3 days before their normal exposure (Zhou et al. 2008a, Snyder et al. 2011, Busada et al. 2014). As shown previously (Busada et al. 2014), exogenous RA induced the precocious expression of differentiation markers STRA8 and KIT by $24 \mathrm{~h}$ (Fig. 7A). However, mRNA levels also transiently increased for Cyp26a1 and Cyp26b1 (Busada et al. 2014), which encode two RA-degrading enzymes, and by $48 \mathrm{~h}$ after treatment, STRA 8 and KIT were absent (Fig. 7B and C), presumably due to loss of all testicular RA signaling. The Cyp26a 1 and Cyp26b1 levels began to normalize by $72 \mathrm{~h}$ after RA exposure, suggesting that the testicular RA environment returned to normal, and germ cells eventually entered meiosis in similar numbers in RA-exposed animals, albeit 2 days later than vehicle-treated controls (Busada et al. 2014). Results from that experiment indicated that expression of STRA8 and KIT did not result in an irreversible commitment to differentiation, but rather that spermatogonia must receive multiple consistent signals to differentiate. To assess this, we followed changes in expression of spermatogonial cell fate markers over the $144 \mathrm{~h}$ following RA exposure at P1.

Exogenous RA induced the precocious appearance of STRA8 +/KIT + spermatogonia by $24 \mathrm{~h}$ (Fig. 7A; Busada et al. 2014) but, by 48 and 72 h post-RA injection, STRA 8 and KIT both became undetectable in spermatogonia (Fig. 7B and C). There were no apparent changes in the expression of the undifferentiated markers ZBTB16 and CDH1 over this interval (Fig. 7E, F, G, H, I, J, K, and L), suggesting that the spermatogonia population had returned to an undifferentiated state following the single exposure to RA. At $144 \mathrm{~h}$ after RA injection, STRA8 and KIT again became detectable in spermatogonia, indicating a resumption of RA signaling (Fig. 7D). Although specific testis cords were either KIT + or KIT - in vehicletreated controls, as in WT (Supplementary Figure S7, see section on supplementary data given at the end of this article), this was largely lost in testes of RA-treated mice (Fig. 7D, H, and L). This resulting similarity in the expression of fate markers suggests homogeneity in differentiation status, and provides an explanation for the widespread synchronization of the seminiferous epithelial cycle observed in adult mice treated with RA as neonates (Snyder et al. 2011, Hogarth et al. 2013).

\section{Discussion}

In this study, we examined the expression of established markers of spermatogonial cell fate in spermatogonia during the first wave of spermatogenesis in the mouse. Importantly, we found that the receptors GFRA1 and KIT, which mark undifferentiated and differentiating spermatogonia, were predominantly localized to distinct cells from P4 onward. This is in contrast to ZBTB16 and $\mathrm{CDH} 1$, markers for undifferentiated spermatogonia in the adult, which were present in nearly all germ cells from P1 through P7. These were also co-localized with the differentiation markers STRA8 and KIT in a subset of spermatogonia at P4, concomitant with the onset of RA signaling. This co-localization of undifferentiated

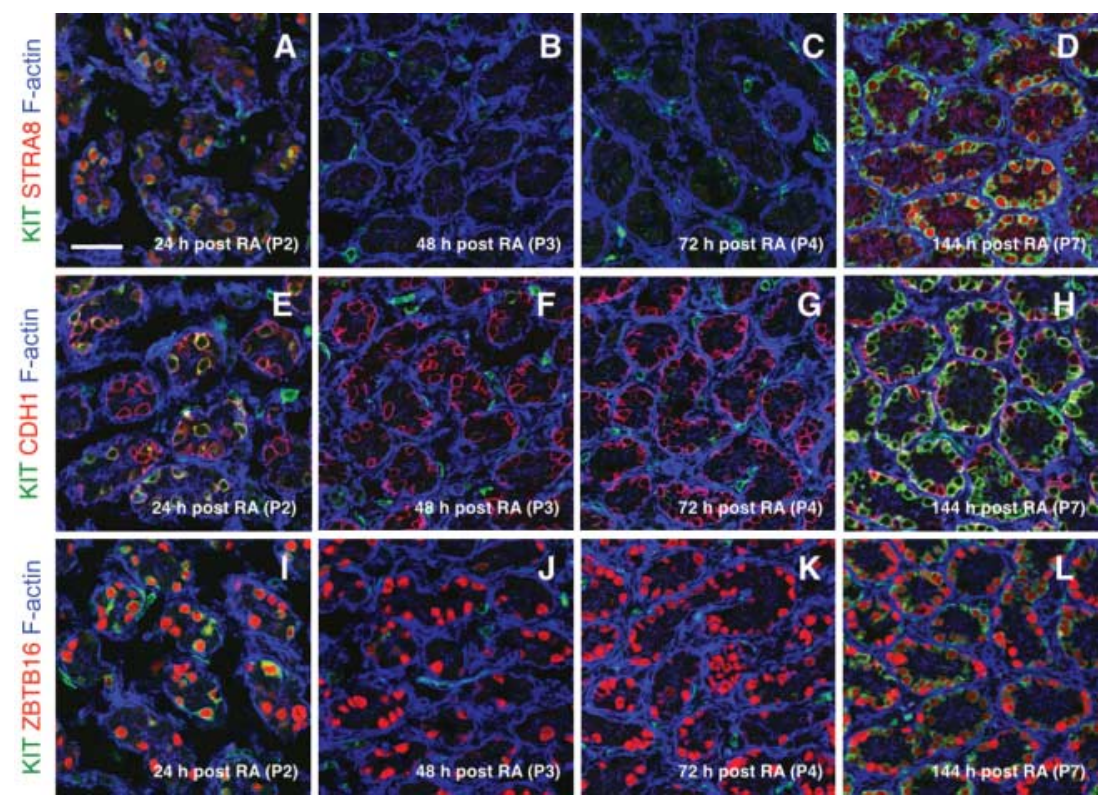

Figure 7 Fate marker changes in germ cells of the neonatal testis following RA-induced differentiation. Phalloidin was used to label F-actin (blue) in all images. Each row contains a temporal detection of RA-induced changes in testis sections. KIT is labeled green in all images, while STRA8 (top row, A, B, C, and D), $\mathrm{CDH} 1$ (middle row, E, F, G, and H), and ZBTB16 (bottom row, I, J, $\mathrm{K}$, and $\mathrm{L}$ ) are labeled in red. The hours after RA injection are indicated on each image, and the actual age is in parentheses. Scale bar $=60 \mu \mathrm{m}$. 


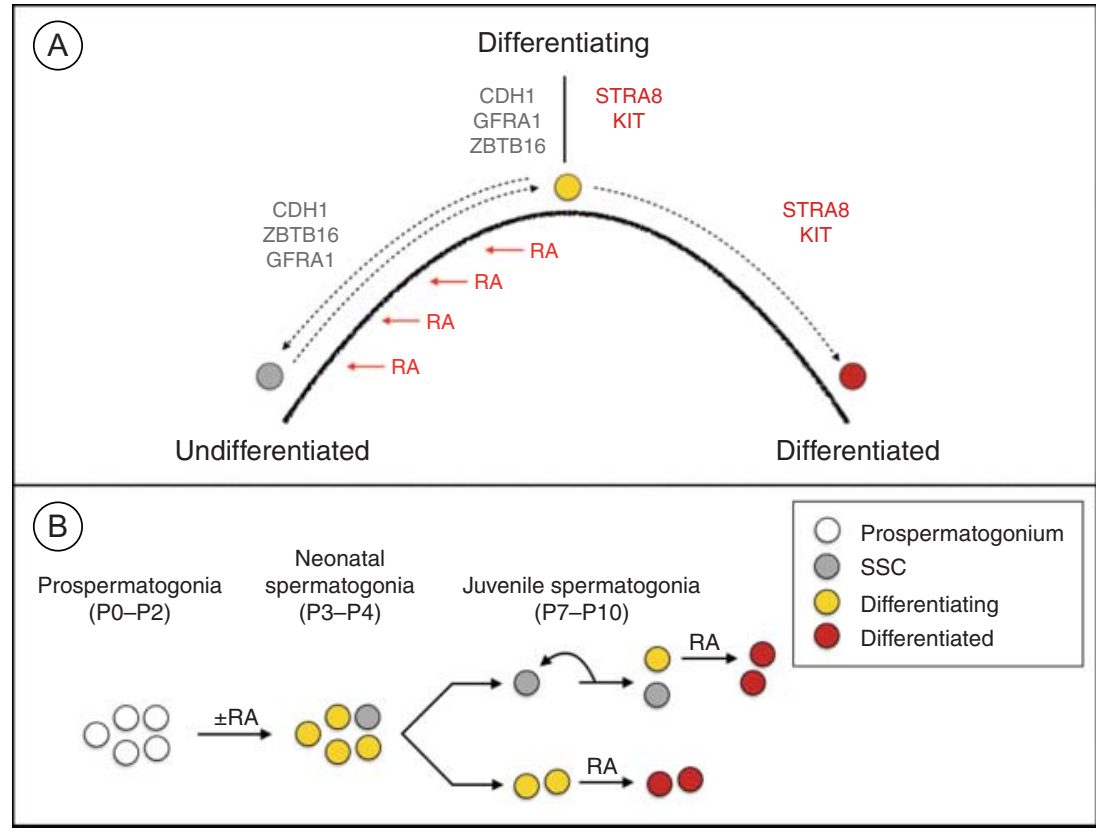

Figure 8 Model for spermatogonial development in the neonatal testis. (A) At P1, prospermatogonia express undifferentiated markers such as $\mathrm{CDH} 1$, ZBTB16, and GFRA1. Following continuous or multiple exposures to RA, differentiating spermatogonia express STRA8 and KIT; a single dosage of RA is not sufficient for differentiation, and spermatogonia appear to revert to the undifferentiated state. (B) Prospermatogonia (white) transition to a heterogeneous population of differentiating and undifferentiated (putative stem cell) spermatogonia. Populations of differentiating spermatogonia enter meiosis, while the SSCs remain undifferentiated to provide a consistent source of differentiated spermatogonia after the first wave of spermatogenesis. and differentiated markers persisted through P10, after which fate marker divergence was observed at P18 and in the adult testis. Taken together, our findings reveal that neonatal spermatogonia are a heterogeneous population as early as P4, and exhibit significant differences in marker expression in comparison with juvenile and adult spermatogonia. These data reveal molecular differences between neonatal and adult spermatogonia that may in part explain functional differences in terms of colonization ability and cell cycle length. In addition, data from this study reveal that caution should be exercised when making conclusions about spermatogonial behavior when utilizing neonatal spermatogonia as a substitute for adult spermatogonia.

The neonatal transition from prospermatogonia to spermatogonia is critical for establishment of spermatogenesis and lifelong male fertility. However, it was unclear when male germ cells begin to show signs of heterogeneity in terms of cell fate markers. We did not detect significant heterogeneity in cell morphology or the expression of cell fate markers in prospermatogonia at P1. Almost none of the prospermatogonia exhibited detectable levels of the differentiation markers STRA8 and KIT, while nearly all prospermatogonia had detectable GFRA1, ZBTB16, and CDH1. This is in agreement with some reports (e.g., ZBTB16 and CDH1 (Costoya et al. 2004, Tokuda et al. 2007)) but in contrast with others (e.g., $\sim 50 \%$ RET + or GFRA $1+$ at P0, although data not shown for GFRA1 (Naughton et al. 2006)). It is possible that, in the latter study, overnight fixation or the harsh tissue processing steps preceding paraffin embedding compromised some of the epitopes for GFRA1 and prevented their detection.

Our data support a model (see Fig. 8A) by which spermatogonia constitutively express undifferentiated markers, and the differentiation program is initiated in response to RA in a subset of cells. Except for GFRA1, these undifferentiated markers persist until at least P7, after which there is significant separation. A similar pattern was observed for SALL4, which is detectable in all spermatogonia through $\mathrm{P} 7$, but then diverges to be expressed in undifferentiated spermatogonia in the adult (Gassei \& Orwig 2013). After exposure to RA in this study, nearly all spermatogonia became STRA8 +/KIT + . However, by $48 \mathrm{~h}$, these differentiation markers were lost, and only undifferentiated markers were constitutively expressed during this period. This suggests that the program of differentiation is initiated in undifferentiated spermatogonia, and that perhaps the most important aspect of commitment to a stem cell fate is avoiding exposure to a differentiation signal such as RA. Indeed, nearly all prospermatogonia exposed to RA (either by culture in excess RA or deletion of the RA-degrading enzyme Cyp26b1) prematurely expressed differentiation markers such as Stra8, Dmc1, Sycp3, Sohlh1, and Kit and attempt to enter meiosis (MacLean et al. 2007, Trautmann et al. 2008, Zhou et al. 2008a,b, Li et al. 2009, Busada et al. 2014). However, we have recently found that the signal provided by a one-time bolus of RA was not sufficient to maintain the differentiated state; by $48 \mathrm{~h}$ after RA injection, all of the neonatal spermatogonia that were previously STRA8+/KIT + had lost expression of both markers and only had detectable undifferentiated markers for at least 3 more days (Busada et al. 2014). As spermatogonia express both undifferentiated and differentiating markers simultaneously, it is reasonable to predict that these cells have not yet committed to the differentiated fate (Fig. 8B). Our results corroborate the concept that multiple, or continuous, 
exposure(s) to RA is necessary to maintain STRA8 and KIT expression.

Beginning at P4, there are at least two distinct populations of spermatogonia that express either the KIT or GFRA1 receptor. The separate expression of these two receptors provides these distinct populations of spermatogonia with the ability to respond differentially to the ligands GDNF and KITL, which are provided by neighboring Sertoli and peritubular myoid cells (Hofmann 2008, Chen et al. 2014). GDNF binds to the GFRA1 and RET co-receptors to regulate SSC maintenance both in vitro and in vivo (Meng et al. 2000, 2001, Viglietto et al. 2000, Kubota et al. 2004, 2011, He et al. 2007). In contrast, KITL binding to KIT is required for spermatogonial differentiation and their subsequent entry into meiosis (Besmer et al. 1993, Kissel et al. 2000, Mithraprabhu \& Loveland 2009). It is potentially the gain of these cell surface receptors, which informs a spermatogonium to remain undifferentiated or to differentiate to eventually enter meiosis. While binding of either ligand to their cognate receptor(s) activates the PI3K/AKT signaling pathway, the distinct outcomes indicate the involvement of different components of this complex pathway.

Taken together, our results indicate that prospermatogonia transition to an initial heterogeneous population of undifferentiated and differentiating spermatogonia by $\sim$ P4. This supports the model whereby prospermatogonia directly give rise to the foundational pool of SSCs (which function to ensure lifelong fertility) as well as the undifferentiated progenitors and differentiating spermatogonia that become spermatozoa during the first wave of spermatogenesis.

\section{Supplementary data}

This is linked to the online version of the paper at http://dx.doi. org/10.1530/REP-14-0653.

\section{Declaration of interest}

The authors declare that there is no conflict of interest that could be perceived as prejudicing the impartiality of the research reported.

\section{Funding}

This work was supported by a grant from the NIH/NICHD (HD072552) to C B Geyer.

\section{Acknowledgements}

The authors thank Joani Zary-Oswald (Brody School of Medicine at East Carolina University) for technical assistance and Dr Brian Hermann (University of Texas at San Antonio) for providing testes obtained from Id4-GFP mice (originally from Dr Jon Oatley, Washington State University).

\section{References}

Bellve AR, Cavicchia JC, Millette CF, O'Brien DA, Bhatnagar YM \& Dym M 1977 Spermatogenic cells of the prepuberal mouse. Isolation and morphological characterization. Journal of Cell Biology 74 68-85. (doi:10.1083/jcb.74.1.68)

Besmer P, Manova K, Duttlinger R, Huang EJ, Packer A, Gyssler C \& Bachvarova RF 1993 The kit-ligand (steel factor) and its receptor c-kit/W: pleiotropic roles in gametogenesis and melanogenesis. Development. Supplement 125-137.

Buaas FW, Kirsh AL, Sharma M, McLean DJ, Morris JL, Griswold MD, de Rooij DG \& Braun RE 2004 Plzf is required in adult male germ cells for stem cell self-renewal. Nature Genetics 36 647-652. (doi:10.1038/ng1366)

Buageaw A, Sukhwani M, Ben-Yehudah A, Ehmcke J, Rawe VY, Pholpramool C, Orwig KE \& Schlatt S 2005 GDNF family receptor $\alpha 1$ phenotype of spermatogonial stem cells in immature mouse testes. Biology of Reproduction 73 1011-1016. (doi:10.1095/biolreprod.105.043810)

Busada JT, Kaye EP, Renegar RH \& Geyer CB 2014 Retinoic acid induces multiple hallmarks of the prospermatogonia-to-spermatogonia transition in the neonatal mouse. Biology of Reproduction 90 64. (doi:10.1095/ biolreprod.113.114645)

Busada J, Chappell V, Niedenberger B, Kaye E, Keiper B, Hogarth C \& Geyer C 2015 Retinoic acid regulates Kit translation during spermatogonial differentiation in the mouse. Developmental Biology 397 140-149. (doi:10.1016/j.ydbio.2014.10.020)

Chan F, Oatley MJ, Kaucher AV, Yang QE, Bieberich CJ, Shashikant CS \& Oatley JM 2014 Functional and molecular features of the Id4 + germline stem cell population in mouse testes. Genes and Development 28 1351-1362. (doi:10.1101/gad.240465.114)

Chen LY, Brown PR, Willis WB \& Eddy EM 2014 Peritubular myoid cells participate in male mouse spermatogonial stem cell maintenance. Endocrinology 155 4964-4974. (doi:10.1210/en.2014-1406)

Costoya JA, Hobbs RM, Barna M, Cattoretti G, Manova K, Sukhwani M, Orwig KE, Wolgemuth DJ \& Pandolfi PP 2004 Essential role of Plzf in maintenance of spermatogonial stem cells. Nature Genetics 36 653-659. (doi:10.1038/ng1367)

Drumond AL, Meistrich ML \& Chiarini-Garcia H 2011 Spermatogonial morphology and kinetics during testis development in mice: a highresolution light microscopy approach. Reproduction 142 145-155. (doi:10.1530/REP-10-0431)

Ebata KT, Zhang X \& Nagano MC 2007 Male germ line stem cells have an altered potential to proliferate and differentiate during postnatal development in mice. Biology of Reproduction 76 841-847. (doi:10. 1095/biolreprod.106.058305)

Gaemers IC, Sonneveld E, van Pelt AM, Schrans BH, Themmen AP, van der Saag PT \& de Rooij DG 1998 The effect of 9-cis-retinoic acid on proliferation and differentiation of a spermatogonia and retinoid receptor gene expression in the vitamin A-deficient mouse testis. Endocrinology 139 4269-4276. (doi:10.1210/endo.139.10.6272)

Gassei K \& Orwig KE 2013 SALL4 expression in gonocytes and spermatogonial clones of postnatal mouse testes. PLOS ONE 8 e53976. (doi:10.1371/journal.pone.0053976)

Grasso M, Fuso A, Dovere L, de Rooij DG, Stefanini M, Boitani C \& Vicini E 2012 Distribution of GFRA1-expressing spermatogonia in adult mouse testis. Reproduction 143 325-332. (doi:10.1530/REP-11-0385)

Grisanti L, Falciatori I, Grasso M, Dovere L, Fera S, Muciaccia B, Fuso A, Berno V, Boitani C, Stefanini M et al. 2009 Identification of spermatogonial stem cell subsets by morphological analysis and prospective isolation. Stem Cells 27 3043-3052. (doi:10.1002/stem.206)

Griswold MD 1998 The central role of Sertoli cells in spermatogenesis. Seminars in Cell \& Developmental Biology 9 411-416. (doi:10.1006/ scdb.1998.0203)

van Haaster LH \& de Rooij DG 1993 Spermatogenesis is accelerated in the immature Djungarian and Chinese hamster and rat. Biology of Reproduction 49 1229-1235. (doi:10.1095/biolreprod49.6.1229)

He Z, Jiang J, Hofmann MC \& Dym M 2007 Gfra1 silencing in mouse spermatogonial stem cells results in their differentiation via the inactivation of RET tyrosine kinase. Biology of Reproduction 77 723-733. (doi:10.1095/biolreprod.107.062513)

Hess RA \& Renato de Franca L 2008 Spermatogenesis and cycle of the seminiferous epithelium. Advances in Experimental Medicine and Biology 636 1-15. (doi:10.1007/978-0-387-09597-4_1) 
Hofmann MC 2008 Gdnf signaling pathways within the mammalian spermatogonial stem cell niche. Molecular and Cellular Endocrinology 288 95-103. (doi:10.1016/j.mce.2008.04.012)

Hogarth CA, Evanoff R, Mitchell D, Kent T, Small C, Amory JK \& Griswold MD 2013 Turning a spermatogenic wave into a tsunami: synchronizing murine spermatogenesis using WIN 18,446. Biology of Reproduction 88 40. (doi:10.1095/biolreprod.112.105346)

Kissel H, Timokhina I, Hardy MP, Rothschild G, Tajima Y, Soares V, Angeles M, Whitlow SR, Manova K \& Besmer P 2000 Point mutation in kit receptor tyrosine kinase reveals essential roles for kit signaling in spermatogenesis and oogenesis without affecting other kit responses. EMBO Journal 19 1312-1326. (doi:10.1093/emboj/19.6.1312)

Kluin PM \& de Rooij DG 1981 A comparison between the morphology and cell kinetics of gonocytes and adult type undifferentiated spermatogonia in the mouse. International Journal of Andrology 4 475-493. (doi:10. 1111/j.1365-2605.1981.tb00732.x)

Kubota H, Avarbock MR \& Brinster RL 2004 Growth factors essential for self-renewal and expansion of mouse spermatogonial stem cells. PNAS 101 16489-16494. (doi:10.1073/pnas.0407063101)

Kubota H, Wu X, Goodyear SM, Avarbock MR \& Brinster RL 2011 Glial cell line-derived neurotrophic factor and endothelial cells promote selfrenewal of rabbit germ cells with spermatogonial stem cell properties. FASEB Journal 25 2604-2614. (doi:10.1096/fj.10-175802)

Li H, MacLean G, Cameron D, Clagett-Dame M \& Petkovich M 2009 Cyp26b1 expression in murine Sertoli cells is required to maintain male germ cells in an undifferentiated state during embryogenesis. PLOS ONE 4 e7501. (doi:10.1371/journal.pone.0007501)

MacLean G, Li H, Metzger D, Chambon P \& Petkovich M 2007 Apoptotic extinction of germ cells in testes of Cyp26b1 knockout mice. Endocrinology 148 4560-4567. (doi:10.1210/en.2007-0492)

Meng X, Lindahl M, Hyvonen ME, Parvinen M, de Rooij DG, Hess MW, Raatikainen-Ahokas A, Sainio K, Rauvala H, Lakso M et al. 2000 Regulation of cell fate decision of undifferentiated spermatogonia by GDNF. Science 287 1489-1493. (doi:10.1126/science.287.5457.1489)

Meng X, de Rooij DG, Westerdahl K, Saarma M \& Sariola H 2001 Promotion of seminomatous tumors by targeted overexpression of glial cell line-derived neurotrophic factor in mouse testis. Cancer Research $613267-3271$.

Mithraprabhu S \& Loveland KL 2009 Control of KIT signalling in male germ cells: what can we learn from other systems? Reproduction 138 743-757. (doi:10.1530/REP-08-0537)

Nagano R, Tabata S, Nakanishi Y, Ohsako S, Kurohmaru M \& Hayashi Y 2000 Reproliferation and relocation of mouse male germ cells (gonocytes) during prespermatogenesis. Anatomical Record 258 210-220. (doi:10.1002/(SICI)1097-0185(20000201)258:2<210::AIDAR10 > 3.0.CO;2-X)

Nagano M, Brinster CJ, Orwig KE, Ryu BY, Avarbock MR \& Brinster RL 2001 Transgenic mice produced by retroviral transduction of male germ-line stem cells. PNAS 98 13090-13095. (doi:10.1073/pnas. 231473498)

Nagano M, Watson DJ, Ryu BY, Wolfe JH \& Brinster RL 2002 Lentiviral vector transduction of male germ line stem cells in mice. FEBS Letters 524 111-115. (doi:10.1016/S0014-5793(02)03010-7)

Nakagawa T, Nabeshima Y \& Yoshida S 2007 Functional identification of the actual and potential stem cell compartments in mouse spermatogenesis. Developmental Cell 12 195-206.

Naughton CK, Jain S, Strickland AM, Gupta A \& Milbrandt J 2006 Glial cell-line derived neurotrophic factor-mediated RET signaling regulates spermatogonial stem cell fate. Biology of Reproduction 74 314-321. (doi:10.1095/biolreprod.105.047365)

Oatley MJ, Kaucher AV, Racicot KE \& Oatley JM 2011 Inhibitor of DNA binding 4 is expressed selectively by single spermatogonia in the male germline and regulates the self-renewal of spermatogonial stem cells in mice. Biology of Reproduction 85 347-356. (doi:10.1095/biolreprod. 111.091330)

Oulad-Abdelghani $M$, Bouillet $P$, Decimo D, Gansmuller A, Heyberger S, Dolle P, Bronner S, Lutz Y \& Chambon P 1996 Characterization of a premeiotic germ cell-specific cytoplasmic protein encoded by Stra8, a novel retinoic acid-responsive gene. Journal of Cell Biology 135 469-477. (doi:10.1083/jcb.135.2.469) van Pelt AM \& de Rooij DG 1991 Retinoic acid is able to reinitiate spermatogenesis in vitamin A-deficient rats and high replicate doses support the full development of spermatogenic cells. Endocrinology $\mathbf{1 2 8}$ 697-704. (doi:10.1210/endo-128-2-697)

Prabhu SM, Meistrich ML, McLaughlin EA, Roman SD, Warne S, Mendis S, Itman C \& Loveland KL 2006 Expression of c-Kit receptor mRNA and protein in the developing, adult and irradiated rodent testis. Reproduction 131 489-499. (doi:10.1530/rep.1.00968)

de Rooij DG 2001 Proliferation and differentiation of spermatogonial stem cells. Reproduction 121 347-354. (doi:10.1530/rep.0.1210347)

de Rooij DG \& Griswold MD 2012 Questions about spermatogonia posed and answered since 2000. Journal of Andrology 33 1085-1095. (doi:10.2164/jandrol.112.016832)

Rothschild G, Sottas CM, Kissel H, Agosti V, Manova K, Hardy MP \& Besmer P 2003 A role for kit receptor signaling in Leydig cell steroidogenesis. Biology of Reproduction 69 925-932. (doi:10.1095/biolreprod. 102.014548)

Snyder EM, Davis JC, Zhou Q, Evanoff R \& Griswold MD 2011 Exposure to retinoic acid in the neonatal but not adult mouse results in synchronous spermatogenesis. Biology of Reproduction 84 886-893. (doi:10.1095/ biolreprod.110.089755)

Suzuki H, Sada A, Yoshida S \& Saga Y 2009 The heterogeneity of spermatogonia is revealed by their topology and expression of marker proteins including the germ cell-specific proteins Nanos2 and Nanos3. Developmental Biology 336 222-231. (doi:10.1016/j.ydbio.2009. 10.002)

Tokuda M, Kadokawa Y, Kurahashi H \& Marunouchi T 2007 CDH1 is a specific marker for undifferentiated spermatogonia in mouse testes. Biology of Reproduction 76 130-141. (doi:10.1095/biolreprod.106.053181)

Trautmann E, Guerquin MJ, Duquenne C, Lahaye JB, Habert R \& Livera G 2008 Retinoic acid prevents germ cell mitotic arrest in mouse fetal testes. Cell Cycle 7 656-664. (doi:10.4161/cc.7.5.5482)

Vergouwen RP, Jacobs SG, Huiskamp R, Davids JA \& de Rooij DG 1991 Proliferative activity of gonocytes, Sertoli cells and interstitial cells during testicular development in mice. Journal of Reproduction and Fertility 93 233-243. (doi:10.1530/jrf.0.0930233)

Viglietto G, Dolci S, Bruni P, Baldassarre G, Chiariotti L, Melillo RM, Salvatore G, Chiappetta G, Sferratore F, Fusco A et al. 2000 Glial cell line-derived neutrotrophic factor and neurturin can act as paracrine growth factors stimulating DNA synthesis of Ret-expressing spermatogonia. International Journal of Oncology 16 689-694. (doi:10.3892/ijo. 16.4.689)

Western P, Miles D, van den Bergen J, Burton M \& Sinclair A 2008 Dynamic regualtion of mitotic arrest in fetal male germ cells. Stem Cells 26 339-347. (doi:10.1634/stemcells.2007-0622)

Yang QE \& Oatley JM 2014 Spermatogonial stem cell functions in physiological and pathological conditions. Current Topics in Developmental Biology 107 235-267. (doi:10.1016/B978-0-12-416022-4. 00009-3)

Yoshida S, Sukeno M, Nakagawa T, Ohbo K, Nagamatsu G, Suda T \& Nabeshima Y 2006 The first round of mouse spermatogenesis is a distinctive program that lacks the self-renewing spermatogonia stage. Development 133 1495-1505. (doi:10.1242/dev.02316)

Zhou Q, Nie R, Li Y, Friel P, Mitchell D, Hess RA, Small C \& Griswold MD 2008a Expression of stimulated by retinoic acid gene 8 (Stra8) in spermatogenic cells induced by retinoic acid: an in vivo study in vitamin A-sufficient postnatal murine testes. Biology of Reproduction 79 35-42. (doi:10.1095/biolreprod.107.066795)

Zhou Q, Li Y, Nie R, Friel P, Mitchell D, Evanoff RM, Pouchnik D, Banasik B, McCarrey JR, Small C et al. 2008b Expression of stimulated by retinoic acid gene 8 (Stra8) and maturation of murine gonocytes and spermatogonia induced by retinoic acid in vitro. Biology of Reproduction 78 537-545. (doi:10.1095/biolreprod.107.064337)

Received 3 October 2014

First decision 27 October 2014

Revised manuscript received 15 December 2014

Accepted 5 January 2015 